\title{
Phylogenetic analysis of Mycobacterium aurum and Mycobacterium neoaurum with redescription of M. aurum culture collection strains
}

Correspondence

Keith E. Simmon

keith.simmon@aruplab.com

\author{
Keith E. Simmon, ${ }^{1}$ Yan Yi Low, ${ }^{2}$ Barbara A. Brown-Elliott, ${ }^{3}$ \\ Richard J. Wallace, $\mathrm{Jr}^{3}$ and Cathy A. Petti ${ }^{1,4}$
}
${ }^{1}$ Associated Regional and University Pathologists (ARUP) Institute for Clinical and Experimental Pathology, Salt Lake City, UT, USA
${ }^{2}$ Associated Regional and University Pathologists (ARUP) Laboratories, Salt Lake City, UT, USA
${ }^{3}$ University of Texas Health Science Center, Department of Microbiology, Tyler, TX, USA
${ }^{4}$ Departments of Medicine and Pathology, University of Utah School of Medicine, Salt Lake City, UT, USA

\begin{abstract}
We examined American Type Culture Collection (ATCC) strains of Mycobacterium aurum and Mycobacterium neoaurum by using multilocus DNA target sequencing. Apart from the type strain, all 10 ATCC $M$. aurum strains examined were classified incorrectly, with most being reclassified as belonging to the $M$. neoaurum-'Mycobacterium lacticola' relatedness group. All four $M$. neoaurum strains were tightly clustered, but heterogeneity was observed within the cluster. As a result of the incorrect annotation of the $M$. aurum strains, two commonly used methods of identification are compromised and two case reports implicating $M$. aurum as a human pathogen are probably incorrect, with the isolates probably belonging to the $M$. neoaurum-' $M$. lacticola' relatedness group. These findings together with a review of isolates identified at two large reference laboratories suggest that $M$. aurum is not a clinically significant isolate.
\end{abstract}

An accurate taxonomic classification of culture collection strains for Mycobacterium species is important for providing the framework for reference databases used in microbiology laboratories. A widely accepted approach for determining the species of Mycobacterium is DNA target sequence analysis with the 16S rRNA gene. However, sequencing multiple DNA targets for identification is an increasingly recognized tool for assigning more accurate taxonomic classifications (Lan \& Reeves, 2001; Maiden et al., 1998) and for describing novel species (Adékambi et al., 2004, 2006a, b). In particular, $r p o B$ and $h s p 65$ genes have served as excellent targets to discriminate closely related Mycobacterium species (Adékambi et al., 2003, 2006a; Williams et al., 2007).

Abbreviations: ARUP, Associated Regional and University Pathologists; ATCC, American Type Culture Collection; PRA, PCR-restriction fragment length polymorphism analysis; UTHSCT, University of Texas Health Science Center.

The GenBank/EMBL/DDBJ accession numbers for the sequences determined in this study are given in Supplementary Table S1 in IJSEM Online.

Neighbour-joining trees based on $r p o B$ and $h s p 65$ gene sequences and a table of the ATCC strains used and GenBank accession numbers for the genes investigated in this study are available as supplementary material with the online version of this paper.
Since 2001, Associated Regional and University Pathologists (ARUP) Laboratories, a large national reference laboratory that provides a service to all 50 United States, have identified Mycobacterium species by sequencing the first $500 \mathrm{bp}$ of the 16S rRNA gene. Upon comparison of sequence-based identifications with a PCR-restriction fragment length polymorphism analysis (PRA) of hsp65 (Devallois et al., 1997; Telenti et al., 1993), we observed discrepancies in the species identifications of Mycobacterium aurum and Mycobacterium neoaurum, which prompted an investigation. In general, a laboratory's confidence in a test result that is based on either gene sequencing or PRA methods increases when isolates share high identity scores or have patterns that match with culture collection strains. The American Type Culture Collection (ATCC) has 11 strains of M. aurum and four strains of $M$. neoaurum. Both $M$. aurum and $M$. neoaurum were described prior to 1975 (Tsukamura \& Mizuno, 1972; Tsukamura \& Tsukamura, 1966) and, to our knowledge, these ATCC strains have not been interrogated by using modern genetic techniques to determine the accuracy of their identification. In this study, we aimed to clarify the phylogenetic relationships of culture collection strains of M. aurum and M. neoaurum.

All available ATCC strains of M. aurum and M. neoaurum were obtained directly from the ATCC, and 19 clinical 
isolates identified by hsp65 PRA as M. aurum or $M$. neoaurum by the University of Texas Health Science Center (UTHSCT) were also obtained from stocks that had been stored at $-70{ }^{\circ} \mathrm{C}$ since isolation. In addition, microbiological records were reviewed for clinical information on all clinical isolates that had been identified as $M$. aurum and $M$. neoaurum between July 2003 and March 2008 at ARUP Laboratories and between January 1995 and March 2008 at UTHSCT. Strains were grown according to the instructions provided by the ATCC. DNA extraction, PCR and sequencing reactions were performed as described previously (Simmon et al., 2007). Amplification and sequencing reactions were performed using primers targeting $\sim 1500 \mathrm{bp}$ of the 16S rRNA gene: 5F (5'-TTGGAGAGTTTGATCCTGGCTC- $\left.3^{\prime}\right)$ and 1492R (5'-ACGGITACCTTGTTACGACTT-3'); and $\sim 750$ bp of rpoB (Adékambi et al., 2003) and $\sim 440$ bp of hsp65 genes (Telenti et al., 1993). PCR products were purified and sequenced as described previously (Simmon et al., 2006). Sequence alignments and phylogenetic trees were constructed using the neighbourjoining method with Kimura's two-parameter distance correction model and 1000 bootstrap replications in the MEGA version 4 software package (Tamura et al., 2007). All clinical isolates were subjected to hsp65 PRA analysis of a 441 bp fragment, as described previously by Telenti et al. (1993). This study was conducted under IRB approved protocols at both ARUP Laboratories and UTHSCT.

\section{Evaluation of $M$. aurum and $M$. neoaurum culture collection strains}

Comparisons of the full 16S rRNA gene sequences from the culture collection strains showed that the type strain of $M$. aurum (ATCC $23366^{\mathrm{T}}$ ) shared very little identity with the other 10 culture collection strains identified as M. aurum (Fig. 1). All four M. neoaurum strains shared high identity with one another, with identical 16S rRNA sequences for the first $500 \mathrm{bp}$ of the gene, with one strain showing $4 \mathrm{bp}$ differences when the entire gene was analysed (Fig. 1). Analysis of the $h s p 65$ and $r p o B$ genes showed heterogeneity among all four $M$. neoaurum strains (Supplementary Fig. S1, available in IJSEM Online). Sequences from the ATCC strains were compared with GenBank references to ascertain the most closely related species for each strain (Table 1). The ATCC $23366^{\mathrm{T}}$ type strain for $M$. aurum differed by $6 \mathrm{bp}$ from the reference sequence from GenBank (X55595), which was derived from the same type strain. The ATCC $23366^{\mathrm{T}}$ type strain did share $100 \%$ identity with the equivalent reference in RIDOM (Ribosomal Differentiation of Medical Microorganisms; http://www.ridom-rdna.de/). This observation was confirmed with repeat testing. Seven strains (ATCC 27277, 25791, 25803, 25800, 25799, 25798, 23071) were most closely related to $M$. neoaurum. The remaining three $M$. aurum ATCC strains shared greater identities with emerging or novel pathogens; namely, Mycobacterium fluoranthenivorans ( $M$. aurum ATCC 23070), 'Mycobacterium petroleophilum' (M. aurum ATCC 21498), and Mycobacterium chlorophenolicum (M. aurum ATCC 25793). Further characterization using $h s p 65$ and rpoB gene sequencing corroborated these phylogenetic relationships. Based on multi-DNA target sequence data and currently accepted practices for mycobacterial identification, we propose that the identification of all $M$. aurum ATCC strains, excluding the type strain of $M$. aurum, should be

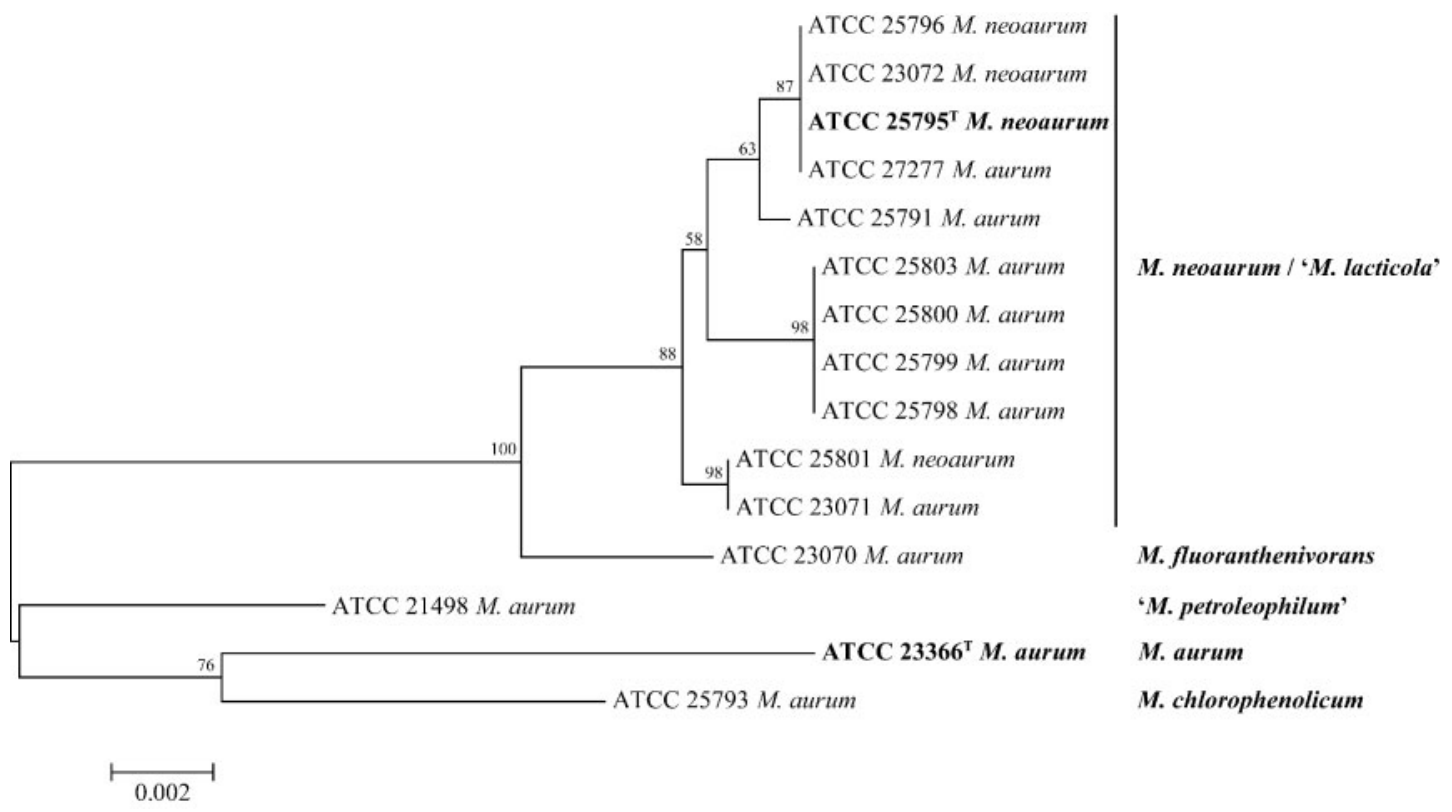

Fig. 1. Neighbour-joining tree based on full 16S rRNA gene sequences with percentage bootstrap values (based on 1000 replications) recorded at each node. Bar, 0.002 substitutions per nucleotide position. 
Table 1. Taxonomic reclassification of ATCC culture collection strains of $M$. aurum and $M$. neoaurum by using full 16S rRNA gene sequencing

\begin{tabular}{|c|c|c|c|c|c|c|}
\hline ATCC number & $\begin{array}{c}\text { ATCC } \\
\text { identification }\end{array}$ & $\begin{array}{l}\text { Top species match } \\
\text { (GenBank number) }\end{array}$ & Per cent identity & $\begin{array}{l}\text { Next species match } \\
\text { (GenBank number) }\end{array}$ & Per cent identity & $\begin{array}{c}\text { Corrected } \\
\text { identification }\end{array}$ \\
\hline 25803 & M. aurum & $\begin{array}{l}\text { 'M. lacticola' ATCC } \\
9626 \text { (AF480582) }\end{array}$ & 100.0 & $\begin{array}{r}\text { M. neoaurum ATCC } \\
25795^{\mathrm{T}}(\mathrm{AF} 480593)\end{array}$ & 99.4 & $\begin{array}{l}\text { M. neoaurum-'M. } \\
\text { lacticola' }\end{array}$ \\
\hline 25800 & M. aurum & $\begin{array}{l}\text { 'M. lacticola' ATCC } \\
9626 \text { (AF480582) }\end{array}$ & 100.0 & $\begin{array}{r}\text { M. neoaurum ATCC } \\
25795^{\mathrm{T}}(\mathrm{AF} 480593)\end{array}$ & 99.4 & $\begin{array}{l}\text { M. neoaurum-'M. } \\
\text { lacticola' }\end{array}$ \\
\hline 25799 & M. aurum & $\begin{array}{l}\text { 'M. lacticola' ATCC } \\
9626 \text { (AF480582) }\end{array}$ & 100.0 & $\begin{array}{r}\text { M. neoaurum ATCC } \\
25795^{\mathrm{T}}(\mathrm{AF} 480593)\end{array}$ & 99.4 & $\begin{array}{l}\text { M. neoaurum-'M. } \\
\text { lacticola' }\end{array}$ \\
\hline 25798 & M. aurum & $\begin{array}{l}\text { 'M. lacticola' ATCC } \\
9626 \text { (AF480582) }\end{array}$ & 100.0 & $\begin{array}{l}\text { M. neoaurum ATCC } \\
25795^{\mathrm{T}}(\mathrm{AF} 480593)\end{array}$ & 99.4 & $\begin{array}{l}\text { M. neoaurum-'M. } \\
\text { lacticola' }\end{array}$ \\
\hline 27277 & M. aurum & $\begin{array}{r}\text { M. neoaurum ATCC } \\
25795^{\mathrm{T}}(\mathrm{AF} 480593)\end{array}$ & 100.0 & $\begin{array}{l}\text { 'M. lacticola' ATCC } \\
9626 \text { (AF480582) }\end{array}$ & 99.4 & $\begin{array}{l}\text { M. neoaurum-'M. } \\
\text { lacticola' }\end{array}$ \\
\hline 25791 & M. aurum & $\begin{array}{l}\text { 'M. lacticola' ATCC } \\
9626 \text { (AF480582) }\end{array}$ & 99.7 & $\begin{array}{r}\text { M. neoaurum ATCC } \\
25795^{\mathrm{T}}(\mathrm{AF} 480593)\end{array}$ & 99.7 & $\begin{array}{l}\text { M. neoaurum-'M. } \\
\text { lacticola' }\end{array}$ \\
\hline 23070 & M. aurum & $\begin{array}{l}\text { M. fluoranthenivor- } \\
\text { ans (AJ617741) }\end{array}$ & 99.3 & $\begin{array}{l}\text { 'M. sacrum' } \\
\text { (AY235429) }\end{array}$ & 99.2 & $\begin{array}{l}\text { Most closely related } \\
\text { to } M . \text { fluorantheni- } \\
\text { vorans }\end{array}$ \\
\hline 21498 & M. aurum & $\begin{array}{l}\text { 'M. petroleophilum' } \\
\text { ATCC } 21497 \\
(\mathrm{AF} 480587)\end{array}$ & 100.0 & $\begin{array}{l}\text { M. gilvum } \\
\text { (CP000656) }\end{array}$ & 99.2 & 'M. petroleophilum' \\
\hline $23366^{\mathrm{T}}$ & M. aurum & $\begin{array}{l}\text { M. aurum ATCC } \\
23366^{\mathrm{T}}(\mathrm{X} 55595)^{\star}\end{array}$ & 99.6 & $\begin{array}{l}\text { M. aichiense } \\
\text { (AF498656) }\end{array}$ & 98.4 & No change \\
\hline 25801 & M. neoaurum & $\begin{array}{r}\text { M. neoaurum ATCC } \\
25795^{\mathrm{T}}(\mathrm{AF} 480593)\end{array}$ & 99.7 & $\begin{array}{l}\text { 'M. lacticola' ATCC } \\
9626 \text { (AF48052) }\end{array}$ & 99.4 & No change \\
\hline 25796 & M. neoaurum & $\begin{array}{r}\text { M. neoaurum ATCC } \\
25795^{\mathrm{T}}(\mathrm{AF} 480593)\end{array}$ & 100.0 & $\begin{array}{l}\text { 'M. lacticola' ATCC } \\
9626 \text { (AF480582) }\end{array}$ & 99.4 & No change \\
\hline
\end{tabular}

${ }^{*}$ Confirmed with repeat testing.

changed to their respective taxonomic identifications as given in Table 1.

\section{Identification of $M$. aurum and $M$. neoaurum by using partial 16S rRNA gene sequencing and hsp65 PRA}

To assess the impact of the incorrectly annotated strains on result reporting, laboratory results from two laboratories performing either partial 16S rRNA gene sequencing or hsp65 PRA analysis were reviewed. Of 7413 mycobacterial isolates identified at ARUP Laboratories, no clinical isolates were identified as $M$. aurum, 20 were identified as belonging to the $M$. neoaurum-' $M$. lacticola' group and one was identified as $M$. chlorophenolicum. Only the M. aurum type strain is available in public and commercial reference databases for $16 \mathrm{~S}$ rRNA gene sequence comparison. The incorrectly annotated ATCC sequences of $M$. aurum, therefore, did not affect the accuracy of laboratory test results using partial $16 \mathrm{~S}$ rRNA gene sequencing. This observation was supported by another large-scale study that identified Mycobacterium spp. by using partial 16S rRNA gene sequencing with the MicroSeq reference database. Of 773 clinical isolates, none were identified as M. aurum (Hall et al., 2003).

Conversely, isolates at UTHSCT were identified by using both phenotypic and PRA methods, and 25 isolates were identified as $M$. neoaurum or $M$. aurum without a definitive result to the species level. The hsp65 PRA database contained three different PRA patterns for $M$. aurum that were derived from strain ATCC $23366^{\mathrm{T}}(M$. aurum), M. aurum strain ATCC 23070 (Devallois et al., 1997) and M. aurum strain CIP 14121.0005 (Telenti et al., 1993). Strain CIP 14121.0005 is no longer listed in the 
Institut Pasteur culture collection and we were unable to retrieve this isolate to verify its identification. None of the 25 UTHSCT clinical isolates matched the hsp65 PRA pattern for the type strain of $M$. aurum, 24 matched the pattern that was more correctly annotated as M. fluoranthenivorans (but also identical to the predicted PRA pattern of M. neoaurum and Mycobacterium frederiksbergense), and the final isolate shared a pattern with the isolate from the Institut Pasteur (Table 2).

\section{Taxonomic concerns}

Although we clarified the taxonomic classifications among M. aurum culture collection strains, our investigations highlighted the need for finer phylogenetic distinctions within the $M$. neoaurum relatedness group. From phylogenetic analyses of $16 \mathrm{~S}$ rRNA, rpoB and $h s p 65$ gene targets, we classified a total of six M. aurum and three $M$. neoaurum culture collection strains in a $M$. neoaurum taxonomic cluster (Fig. 1). Of particular concern was the distinction between M. neoaurum and ' $M$. lacticola', the name of which to date is not validly published, but has been reported in the literature (Kiska et al., 2004). With full 16S rRNA gene sequencing, $M$. aurum strains ATCC 25803, 25800, 25799 and 25798 shared $100 \%$ identity with the type strain of ' $M$. lacticola', which differed by 8 bp from the type strain of M. neoaurum. With the hsp 65 and rpoB targets, these four ATCC isolates remained closely clustered as ' $M$. lacticola' group, but intraspecies variability differed $(0.7 \%$ for hsp65 and $1.5 \%$ for rpoB). Further phylogenetic distinctions for the remaining seven ATCC strains that comprise the $M$. neoaurum relatedness group could not be determined reliably in the absence of genealogical concordance among the three targets. We propose that all 11 culture collection strains as annotated in Fig. 1 be considered part of the $M$. neoaurum and ' $M$. lacticola' relatedness groups, until studies are performed to evaluate their larger genomic differences and determine their biological relevance.

\section{Clinical impact}

Only two case reports have been reported in the literature that implicate $M$. aurum as a cause of infection, both of which were catheter-related bloodstream infections. (Esteban et al., 1998; Koranyi \& Ranalli, 2003). Esteban et al. (1998) did not specify their method of identification, and Koranyi \& Ranalli (2003) reported the performance of high-performance liquid chromatography (HPLC). Of note, the published method for mycobacterial identification by HPLC includes the ATCC 25793 M. aurum strain, which is more closely related to $M$. chlorophenolicum (Butler \& Guthertz, 2001). Without the benefit of a molecular-based test, we question the accuracy of identification methods from these two case reports. In addition, not finding $M$. aurum among any clinical isolates from our current and other longitudinal studies (Hall et al., 2003) adds to our uncertainty that $M$. aurum is associated with invasive disease. It should also be noted that the type strain of M. aurum was isolated from soil and not associated with human disease (Tsukamura \& Tsukamura, 1966). On the other hand, M. neoaurum has been well-recognized as a human pathogen associated with meningoencephalitis (Heckman et al., 2004) and catheter-related bloodstream infections in immunocompromised hosts (Washer et al., 2007).

We conclude that, except for the type strain, ATCC culture collection strains of $M$. aurum are incorrectly annotated. We also demonstrate that partial 16S rRNA gene sequencing is unaffected by these errors and can reliably distinguish between M. aurum and M. neoaurum as public and commercial databases currently have only sequences from the ATCC M. aurum type strain. Conversely, identification by hsp65 PRA analysis can lead to inaccurate classification of isolates as $M$. aurum because reference patterns are derived from erroneously annotated ATCC strains. Laboratories using this method should modify their reference set based on our identifications shown in Table 2. Finally, we propose that the majority of $M$. aurum strains belong to the $M$. neoaurum-'M. lacticola' relatedness

Table 2. Comparison of clinical isolates identified by using $h s p 65$ PRA and $16 \mathrm{~S}$ rRNA gene sequencing analyses

$\mathrm{NA}$, Not applicable.

\begin{tabular}{|c|c|c|c|c|}
\hline $\begin{array}{l}\text { PRA pattern attributed to } \\
\text { M. aurum }\end{array}$ & $\begin{array}{c}\text { Source of PRA reference } \\
\text { pattern for M. aurum }\end{array}$ & No. of clinical isolates & $\begin{array}{l}\text { Identification by partial } \\
\text { 16S rRNA (\% identity)* }\end{array}$ & $\begin{array}{c}\text { Identification by full } \\
\text { 16S rRNA gene ( } \% \text { identity) }\end{array}$ \\
\hline I & ATCC $23366^{\mathrm{T}}$ & 0 & NA & NA \\
\hline II & ATCC 23070 & 24 & $\begin{array}{l}16 \text { M. neoaurum; } 3 \text { M. } \\
\text { frederiksbergense }(100 \%)\end{array}$ & $\begin{array}{l}16 \text { M. neoaurum; } 2 \mathrm{M} . \\
\text { fluoranthenivorans } \\
(99.3 \%) ; 1 \mathrm{M} \text {. frederiksber- } \\
\text { gense }(99.2 \%)\end{array}$ \\
\hline III & CIP 14121.0005 & 1 & Mycobacterium sp. (98.7\%) & Mycobacterium sp. (98.5\%) \\
\hline
\end{tabular}

${ }^{\star} 19$ of the 24 isolates were analysed by using $16 \mathrm{~S}$ rRNA gene sequencing, the remaining five were not available for further analysis. 
group. Further phylogenetic distinctions within this group cannot be made with $16 \mathrm{~S}$ rRNA, hsp65 and rpoB gene targets because of a lack of genealogical concordance and a high degree of intraspecies variability. Further study is warranted to better define the need for greater phylogenetic distinctions within the M. neoaurum-'M. lacticola' group.

\section{Acknowledgements}

We thank Linda Bridge Mann, Rebecca Wilson, Maria McGlasson and Lametrica Battee at the University of Texas Health Science Center at Tyler, Mycobacteria/Nocardia Laboratory for their laboratory assistance.

\section{References}

Adékambi, T., Colson, P. \& Drancourt, M. (2003). rpoB-based identification of nonpigmented and late-pigmenting rapidly growing mycobacteria. J Clin Microbiol 41, 5699-5708.

Adékambi, T., Reynaud-Gaubert, M., Greub, G., Gevaudan, M. J., La Scola, B., Raoult, D. \& Drancourt, M. (2004). Amoebal coculture of "Mycobacterium massiliense" sp. nov. from the sputum of a patient with hemoptoic pneumonia. J Clin Microbiol 42, 5493-5501.

Adékambi, T., Berger, P., Raoult, D. \& Drancourt, M. (2006a). rpoB gene sequence-based characterization of emerging non-tuberculous mycobacteria with descriptions of Mycobacterium bolletii sp. nov., Mycobacterium phocaicum sp. nov. and Mycobacterium aubagnense sp. nov. Int J Syst Evol Microbiol 56, 133-143.

Adékambi, T., Raoult, D. \& Drancourt, M. (2006b). Mycobacterium barrassiae sp. nov., a Mycobacterium moriokaense group species associated with chronic pneumonia. J Clin Microbiol 44, 3493-3498.

Butler, W. R. \& Guthertz, L. S. (2001). Mycolic acid analysis by high-performance liquid chromatography for identification of Mycobacterium species. Clin Microbiol Rev 14, 704-726.

Devallois, A., Goh, K. S. \& Rastogi, N. (1997). Rapid identification of mycobacteria to species level by PCR-restriction fragment length polymorphism analysis of the $h s p 65$ gene and proposition of an algorithm to differentiate 34 mycobacterial species. J Clin Microbiol 35, 2969-2973.

Esteban, J., Fernandez-Roblas, R., Roman, A., Molleja, A., Jimenez, M. S. \& Soriano, F. (1998). Catheter-related bacteremia due to Mycobacterium aurum in an immunocompromised host. Clin Infect Dis 26, 496-497.

Hall, L., Doerr, K. A., Wohlfiel, S. L. \& Roberts, G. D. (2003). Evaluation of the MicroSeq system for identification of mycobacteria by $16 \mathrm{~S}$ ribosomal DNA sequencing and its integration into a routine clinical mycobacteriology laboratory. J Clin Microbiol 41, 1447-1453.

Heckman, G. A., Hawkins, C., Morris, A., Burrows, L. L. \& Bergeron, C. (2004). Rapidly progressive dementia due to Mycobacterium neoaurum meningoencephalitis. Emerg Infect Dis 10, 924-927.

Kiska, D. L., Turenne, C. Y., Dubansky, A. S. \& Domachowske, J. B. (2004). First case report of catheter-related bacteremia due to "Mycobacterium lacticola". J Clin Microbiol 42, 2855-2857.

Koranyi, K. I. \& Ranalli, M. A. (2003). Mycobacterium aurum bacteremia in an immunocompromised child. Pediatr Infect Dis J 22, 1108-1109.

Lan, R. \& Reeves, P. R. (2001). When does a clone deserve a name? A perspective on bacterial species based on population genetics. Trends Microbiol 9, 419-424.

Maiden, M. C., Bygraves, J. A., Feil, E., Morelli, G., Russell, J. E., Urwin, R., Zhang, Q., Zhou, J., Zurth, K. \& other authors (1998). Multilocus sequence typing: a portable approach to the identification of clones within populations of pathogenic microorganisms. Proc Natl Acad Sci U S A 95, 3140-3145.

Simmon, K. E., Croft, A. C. \& Petti, C. A. (2006). Application of SmartGene IDNS software to partial 16S rRNA gene sequences for a diverse group of bacteria in a clinical laboratory. J Clin Microbiol 44, 4400-4406.

Simmon, K. E., Pounder, J. I., Greene, J. N., Walsh, F., Anderson, C. M., Cohen, S. \& Petti, C. A. (2007). Identification of an emerging pathogen, Mycobacterium massiliense, by rpoB sequencing of clinical isolates collected in the United States. J Clin Microbiol 45, 1978-1980.

Tamura, K., Dudley, J., Nei, M. \& Kumar, S. (2007). MEGA4: Molecular Evolutionary Genetics Analysis (MEGA) software version 4.0. Mol Biol Evol 24, 1596-1599.

Telenti, A., Marchesi, F., Balz, M., Bally, F., Bottger, E. C. \& Bodmer, T. (1993). Rapid identification of mycobacteria to the species level by polymerase chain reaction and restriction enzyme analysis. J Clin Microbiol 31, 175-178.

Tsukamura, M. \& Mizuno, S. (1972). A new species of rapidly growing scotochromogenic mycobacteria. Mycobacterium neoaurum. Med Biol (Tokyo) 85, 229-233.

Tsukamura, M. \& Tsukamura, S. (1966). Mycobacterium aurum; a new species. Igaku To Seibutsugaku 72, 270-273.

Washer, L. L., Riddell, J., Rider, J. \& Chenoweth, C. E. (2007). Mycobacterium neoaurum bloodstream infection: report of 4 cases and review of the literature. Clin Infect Dis 45, e10-e13.

Williams, K. J., Ling, C. L., Jenkins, C., Gillespie, S. H. \& McHugh, T. D. (2007). A paradigm for the molecular identification of Mycobacterium species in a routine diagnostic laboratory. J Med Microbiol 56, 598-602. 